University of Montana

ScholarWorks at University of Montana

$1-2001$

\title{
Abiotic vs. Biotic Influences on Habitat Selection of Coexisting Species: Climate Change Impacts?
}

Thomas E. Martin

University of Montana - Missoula, tom.martin@umontana.edu

Follow this and additional works at: https://scholarworks.umt.edu/wildbio_pubs

Part of the Life Sciences Commons

Let us know how access to this document benefits you.

\section{Recommended Citation}

Martin, Thomas E., "Abiotic vs. Biotic Influences on Habitat Selection of Coexisting Species: Climate Change Impacts?" (2001). Wildlife Biology Faculty Publications. 21.

https://scholarworks.umt.edu/wildbio_pubs/21

This Article is brought to you for free and open access by the Wildlife Biology at ScholarWorks at University of Montana. It has been accepted for inclusion in Wildlife Biology Faculty Publications by an authorized administrator of ScholarWorks at University of Montana. For more information, please contact scholarworks@mso.umt.edu. 


\title{
ABIOTIC VS. BIOTIC INFLUENCES ON HABITAT SELECTION OF COEXISTING SPECIES: CLIMATE CHANGE IMPACTS?
}

\author{
Thomas E. Martin \\ United States Geological Survey, Biological Resources Division, Montana Cooperative Wildlife Research Unit, \\ Avian Studies Program, University of Montana, Missoula, Montana 59812 USA
}

\begin{abstract}
Species are commonly segregated along gradients of microclimate and vegetation. I explore the question of whether segregation is the result of microhabitat partitioning (biotic effects) or choice of differing microclimates (abiotic effects). I explored this question for four ground-nesting bird species that are segregated along a microclimate and vegetation gradient in Arizona. Birds shifted position of their nests on the microhabitat and microclimate gradient in response to changing precipitation over nine years. Similarly, annual bird abundance varied with precipitation across $12 \mathrm{yr}$. Those shifts in abundance and nesting microhabitat with changing precipitation demonstrate the importance of abiotic influences on bird distributions and habitat choice. However, nest-site shifts and microhabitat use also appear to be influenced by interactions among coexisting species. Moreover, shifts in habitat use by all species caused nest predation (i.e., biotic) costs that increased with increasing distance along the microclimate gradient. These results indicate that abiotic and biotic costs can strongly interact to influence microhabitat choice and abundances of coexisting species. Global climate change impacts have been considered largely in terms of simple distributional shifts, but these results indicate that shifts can also increase biotic costs when species move into habitat types for which they are poorly adapted or that create new biotic interactions.
\end{abstract}

Key words: Arizona; global climate change; ground-nesting birds; microclimate gradient; microhabitat segregation; nest-site selection; physiological tolerances; resource partitioning.

\section{INTRODUCTION}

The relative importance of abiotic vs. biotic influences on distributions of species, habitat selection, and species coexistence were argued long ago (e.g., Clements 1916, Gleason 1917, 1926, Grinnell 1917, 1924). In recent decades, attention has focused on biotic interactions, especially to explain differences in habitat use among coexisting species (e.g., MacArthur 1958, Holt 1977, 1984, Pimm and Rosenzweig 1981, Rosenzweig 1981, 1985, Martin 1986, 1996). Yet, differences in resource use among coexisting species could reflect differences in evolutionary histories (e.g., Grinnell 1917, 1924, James et al. 1984, Martin 1986, Wiens 1989). For example, differences in evolutionary histories can yield differing physiological tolerances that may favor differing geographic distributions or habitat use of species based on underlying climate (e.g., Hinds and Calder 1973, Hayworth and Weathers 1984, Root $1988 a, b$, Weathers and Greene 1998). Eggs and young are sensitive to microclimate in many taxa (e.g., D. Webb 1987, Haftorn 1988, Hays and Speakman 1993, Hecnar 1994, Shine et al. 1995) and nest-site choice can be influenced by microclimate (Horvath 1964, Hadley 1969, Calder 1973, Walsberg 1981, 1985, With and Webb 1993, Shine and Harlow 1996). Thus, differences in nest-site choice of coexisting species along micro-

Manuscript received 21 December 1998; revised 15 October 1999; accepted 17 November 1999; final version received 13 December 1999. climate gradients could reflect responses to the underlying abiotic gradient, but such effects are largely unstudied.

On the other hand, nest-patch choice often influences risk of predation or parasitism of young in a variety of taxa based on habitat characteristics of the reproductive patch (Howard 1978, Whitham 1980, Stewart and Pough 1983, Martin and Roper 1988, Martin 1993, 1998; but see Holway 1991, Howlett and Stutchbury 1997). Moreover, overlap in habitat characteristics of nest patches among coexisting species can increase risk of nest predation and, thereby, favor differences in microhabitat use among coexisting species (Martin $1988 a, b, 1996)$. Thus, biotic effects also have the potential to influence nest-site selection, emphasizing the need to examine the independent and interacting roles of biotic and abiotic influences on nest-site selection among coexisting species.

The relative importance and potential interaction of biotic and abiotic influences on habitat use has important implications for possible ecological consequences of global climate change. Climate change is widely predicted to cause shifts in distributions of species along latitudinal or other climatic gradients because species are expected to track climate as a function of their physiological tolerances (Davis et al. 1986, T. Webb 1987, Pastor and Post 1988, Graham and Grimm 1990, Davis and Zabinski 1992, Hart and Shaw 1995, Root and Schneider 1995). Such shifts are expected to 
minimize physiological costs of changing climate. Distributional shifts, on the other hand, can cause occupation of new or different vegetation and animal species associations that may change biotic interactions and impose demographic costs (Lodge 1993). Yet, such effects are undocumented. Of course, demographic costs may be minimal because animals may only shift their distributions within bounds set by the distribution of vegetation to which they are adapted (Grinnell 1917, James et al. 1984, Root 1988a, $b$, Root and Schneider 1995). Thus, two critical questions need to be answered: (1) Do animals shift their distributions with changing abiotic (climate) conditions independent of vegetation and biotic interactions? (2) Do distributional shifts incur demographic costs from biotic interactions?

Microclimate gradients provide a powerful system to study relative roles of abiotic vs. biotic interactions on microhabitat segregation among coexisting species, as well as questions about possible demographic costs of shifting distributions. Bird, mammal, reptile, amphibian, and insect species are commonly segregated along microclimate gradients and those gradients usually also reflect vegetation gradients (e.g., Smith 1977 , Karr and Freemark 1983, Toft 1985, Johnson 1992, Martin 1993, 1998). Segregation, thus, could reflect choice of differing microclimates because of differing physiological tolerances or it could reflect choice of differing vegetation characteristics due to biotic influences. Moreover, large scale distributions (i.e., geographic ranges) are commonly mimicked on local gradients. For example, Orange-crowned Warblers (Vermivora celata) largely occur in cold and damp northern regions whereas Virginia's Warblers (Vermivora virginiae) occur more commonly in warm and dry southern regions (Peterson 1990). These two congeners show the same distributions along a local microclimate gradient in high elevation $(2400 \mathrm{~m})$ forest valleys in Ar- izona where they coexist (Fig. 1). Local distribution and microhabitat selection can thus potentially parallel (and reflect) larger scale patterns, but the local scale is more tractable for examining biotic interactions and demographic costs that may arise with shifting distributions.

Here, I examine microhabitat use and local distributions of four ground-nesting passerines that are segregated in their nest-site preferences along a well-defined microclimate and vegetation gradient (Fig. 1). I examine whether (1) microhabitat use and local distributions shift with changes in weather, (2) such shifts are constrained by vegetation preferences, and (3) such shifts incur demographic costs from biotic interactions.

\section{Study Area And Methods}

\section{Study area}

Study sites were snow-melt drainages located on the Mogollon Rim in central Arizona at $\sim 2400$ m elevation. Canopy trees were quaking aspen (Populus tremuloides), Douglas-fir (Pseudotsuga menziesii), white fir (Abies concolor), ponderosa pine (Pinus ponderosa), white pine (Pinus strobiformis), and Gambel's oak (Quercus gambellii). The understory included canyon maple (Acer grandidentatum), New Mexican locust (Robinia neomexicana), saplings of overstory tree species, golden pea (Thermopsis pinetorum), and various grasses. Those drainages contrast with surrounding forest, which is characterized by open ponderosa pine with Gambel's oak in the subcanopy and little understory vegetation. The study sites include 20 snowmelt drainages, which provide a set of replicated microhabitat and microclimate gradients. A cross section of each study drainage varies predictably in plant species composition from mesic plants in the bottom to xeric plants at the ridgetops. In particular, ground cover and stem

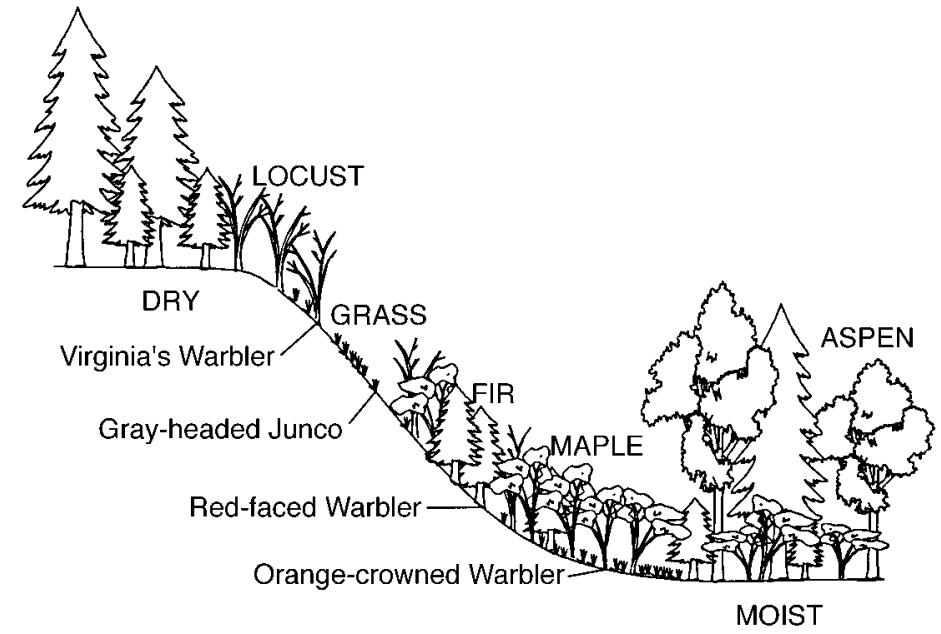

FIG. 1. Characterization of a vegetation gradient for forest drainages in Arizona. New Mexican locust (Robinia neomexicana) is xeric tolerant and was more abundant at the top than in the bottom of drainages (Martin 1998). Canyon maple (Acer grandidentatum) is associated with mesic conditions and was more abundant in the bottom than at the top of drainages (Martin 1998). Small ( $<3 \mathrm{~m}$ in height) firs (Abies concolor, Pseudotsuga menziesii) were similar in abundance over the entire gradient. The four ground-nesting bird species that coexist in these drainages exhibit clear nest site preferences that differ across this microclimate/vegetation gradient (Martin 1996, 1998). In general, Virginia's Warblers prefer xeric microhabitats dominated by locust high on slopes. Gray-headed Juncos prefer open grassy sites with an abundance of locust, indicating a tendency toward xeric sites. Red-faced Warblers prefer more mesic sites dominated by small firs and maple relatively low on the slope, and Orange-crowned Warblers prefer mesic microhabitats dominated by maple low on the slope (Martin 1998). 
densities of maple and aspen decrease from bottom to top of the drainage (Martin 1998), as they are associated with more mesic conditions (e.g., Peattie 1953 , Barker 1977, Barker et al. 1982). In contrast, locust and oak, which are shade intolerant and xeric tolerant (Peattie 1953, Isely and Peabody 1984), increase from bottom to top of the drainages (Martin 1998). Midslope represents a transition area that includes a mix of plants from mesic and xeric portions (see Fig. 1 and Martin 1998). Thus, vegetation is a gradient that also reflects a moisture gradient. This gradient is relatively short $(<100 \mathrm{~m}$ in all cases $)$ such that territories of all individuals of all species encompassed the entire gradient. Thus, each individual had the entire gradient from which to choose their nest sites in every year, and the entire gradient was available for foraging in every year.

Four bird species nest on the ground on these sites: Virginia's Warbler (Vermivora virginiae), Gray-headed Junco (Junco hyemalis caniceps), Red-faced Warbler (Cardellina rubifrons), and Orange-crowned Warbler (Vermivora celata). These species are segregated along the vegetation and microclimate gradient (see Fig. 1 and Martin 1998). Virginia's Warblers nest highest in xeric vegetation. Gray-headed Juncos are next most xeric, but occupy a wide range of topographic positions. Red-faced Warblers nest in the lower portion of the slope and Orange-crowned Warblers nest lowest on the slope in mesic vegetation (Fig. 1 and Martin 1998).

Potential nest predators include red squirrels (Tamiasciurus hudsonicus), gray-necked chipmunks (Eutamias cinereicollis), long-tailed weasels (Mustela frenata), House Wrens (Troglodytes aedon), and Steller's Jays (Cyanocitta stelleri). General observations on the sites and photographic records at artificial nests indicate that red squirrels and gray-necked chipmunks are the primary predators (Martin 1988b, 1993).

\section{Field work}

Birds were counted on 10 plots from 1985 and through 1997 to provide an index of annual changes in abundance on the study plots. More (20) plots were studied beginning in 1988 to enhance sample sizes for nests, but were not included in count estimates. Singing males were counted from mid-May to end of June in each year beginning in 1985 using a plot mapping technique described by Christman (1984); birds were mapped within a $100-\mathrm{m}$ belt transect (i.e., $50 \mathrm{~m}$ to each side) marked at 25-m intervals down the center of each study site. All counts were made between one-half hour before sunrise to four hours after sunrise. Each site was visited a minimum of two times for plot map counts. Each plot was counted once before returning to any plot to minimize any seasonal effects. Moreover, plot map counts were supplemented by territory mapping of each plot by nest-searching field assistants that visited each plot every other day during May and June. Territory maps were used to supplement counts with territories that were missed in plot map counts; on av- erage, plot map counts accounted for 85 to $100 \%$ of birds detected by territory maps.

Study drainages were searched for nests of all bird species from beginning of May until end of July from 1988 to 1997; data were not gathered in 1990 due to a lapse in funding. Nests were located by following adults as described by Martin and Geupel (1993). Date and status (e.g., nest building, presence of parents, eggs, nestlings) were recorded every 3-4 d. Nests that fledged at least one young were considered successful. Observations of nestlings within $2 \mathrm{~d}$ of fledging age, fledglings near the nest, or parents feeding fledglings in the general area of the nest were taken as evidence of a successful nest. Depredation was assumed when eggs or nestlings (when too young to fledge) disappeared. Daily survival and mortality rates were estimated following Mayfield (1975), Johnson (1979), and Hensler and Nichols (1981). Half the number of days between subsequent visits in which a nest was depredated was added to number of previous days the nest survived to obtain exposure days.

Microhabitat was measured generally following the Breeding Biology Research and Monitoring Database (BBIRD) sampling protocol (T. E. Martin, C. R. Paine, C. J. Conway, and W. Hochachka; unpublished manuscript). Briefly, vegetation was measured on three sampling frames: (1) nest sites, (2) nonuse sites, and (3) stratified random sites (stratified across three strata; lower, middle, and upper one-third of the sides of drainages). Here, I present data only for nest sites; data for nonuse sites and stratified random sites are presented in Martin (1998). Vegetation features at nest sites were measured in a sampling plot centered on the nest. Habitat was measured in a $5 \mathrm{~m}$ radius circle nested in an $11 \mathrm{~m}$ radius circle centered on the nest. The $5 \mathrm{~m}$ radius circle was used to count understory plants and the 11 $m$ radius circle was used for canopy trees. Numbers of stems of all understory woody plant species were counted separately by species and by size classes: $<2.5$ $\mathrm{cm} \mathrm{dbh}, 2.5-8 \mathrm{~cm} \mathrm{dbh}$, and $8-23 \mathrm{~cm}$ dbh. Small conifers (Douglas-firs, white firs, ponderosa pines, white pines) in the understory were counted by height classes: $<1 \mathrm{~m}$ tall, 1-3 $\mathrm{m}$ tall, and 3-5 $\mathrm{m}$ tall. Canopy trees were counted in the $11 \mathrm{~m}$ radius circle at the following sizes: $8-23 \mathrm{~cm} \mathrm{dbh}, 23-38 \mathrm{~cm} \mathrm{dbh}$, and $>38 \mathrm{~cm} \mathrm{dbh}$. The $5 \mathrm{~m}$ radius circle was divided into four sections using string and stakes to increase accuracy of counts and to eliminate duplicate counts of shrub stems. In addition, percentage ground cover comprised of green vegetation was measured in each quadrant by ocular estimation and averaged over all four quadrants.

Each nest site was classified in one of three strata (lower, middle, or upper one-third) on the sides of drainages as a measure of topographic position starting in 1993. The microclimate gradient was characterized at the bottom and top of the gradient in microhabitats typical of bird species; Vaisalia CS-5000 temperature and relative humidity probes (Vaisalia, Boulder, Col- 
orado, USA) were placed $5 \mathrm{~cm}$ above ground under shade in permanent sites each year near the bottom of the slope in a maple patch and at the top of the slope in a locust patch typical of Orange-crowned and Virginia's warblers, respectively (see Martin 1998). Campbell Scientific CR-10 (Logan, Utah, USA) dataloggers were used to record temperature and relative humidity at 30-s intervals averaged over each $5 \mathrm{~min}$.

Variation in macroclimate among years was measured using National Ocean and Atmospheric Administration data from Chevlon Ranger Station (formerly Wallace Ranger Station), $\sim 8 \mathrm{~km}$ from the study sites. The earliest individuals of the earliest species (Orangecrowned Warbler, Gray-headed Junco) begin migrating through and arriving on the study sites in the last week of April, with most individuals arriving in early May and another wave in late May. The other species arrive and establish territories in mid- to late-May and early June. May is much wetter than June and the vast majority of June precipitation falls in early June when some birds are still arriving, establishing territories, and choosing nest sites. Consequently, macroclimate was measured as total precipitation and minimum, maximum, and mean temperature during May and June as the primary months of territory establishment and nest initiation. I also checked possible effects of early weather by examining cumulative precipitation (see Results for importance of precipitation) in January through April and April + May. Data were also obtained for $50 \mathrm{yr}$ prior to 1985 to provide a long-term contrast to annual study years.

\section{Data analyses}

Discriminant function and correlation analyses of random samples $(N=303)$ among strata were used to reduce number of habitat variables based on multicollinearity (see Martin 1998). Densities of different size classes of the same plant species showed strong positive correlations among strata and sampling sites. Hence, size classes of plant species were lumped. Also, Douglas-fir vs. white fir and white pine vs. ponderosa pine each showed positive correlations and were lumped as firs and pines, respectively. Previous analyses (Martin 1998) show that each bird species prefers a dominant microhabitat type and four main types differentiated nest preferences and nest-site use of the four bird species: maple (the nest was placed under maple and $>50 \%$ of stems were maple); fir (nests were placed at the base of a small fir and $>40 \%$ of stems were small firs); open (nests were not placed under or near a woody stem and instead were placed in the open); locust (the nest was placed under a locust stem and $>40 \%$ of stems were locust). Thus, nest-site use, for purposes of this paper, was based on those previous detailed analyses and the four microhabitat types that characterize $>98 \%$ of nest-site use by these four bird species (see Martin 1998).

Each of the nine years that nests were studied was categorized as wet or dry based on comparing May + June precipitation in each year against the mean for the previous $50 \mathrm{yr}$. Years where precipitation exceeded or were less than the 50-yr mean were categorized as wet or dry. Percentages of nests placed in each of the three strata (lower, middle, and upper one-third of the slope) were compared between the wet year of 1994 (topographic data were not collected prior to 1993) and the dry year of 1996 to examine topographic shifts in nest placement using likelihood ratio chi-square analyses.

Percentages of nests placed in maple-dominated and locust-dominated (the mesic vs. xeric ends of the gradient) habitat patches were compared between wet and dry years using Analysis of Variance (ANOVA) after arc-sine transformation. Then, percentages of nests placed in maple-dominated and locust-dominated habitat patches were regressed against total precipitation during May and June for each species over the nine years of study. Regressions were analyzed as linear and log-transformed to check for curvilinear effects; results are reported for log-transformed when those models explained more variance in the data.

Differences in daily mortality rates among species or among the four microhabitat types were tested using program CONTRAST (Hines and Sauer 1989). This program uses a chi-square approach that is analogous to ANOVA to control for experiment-wise error and adjust for Type I errors (Hines and Sauer 1989).

I approximated the nesting success necessary to maintain populations ( $\lambda=1)$ using deterministic population growth $(\lambda)$ isoclines from projection matrix modeling for the four species (Martin et al. 1996a). Annual adult survival was estimated for Orangecrowned Warblers as 0.64 (T. Martin, unpublished data), 0.65 for Red-faced Warblers, and 0.56 for Grayheaded Juncos (Martin 1995). Survival for Virginia's Warblers was estimated as 0.65 based on data for similar ground-nesting species in Martin (1995). I used the following fecundity data based on study of these species (T. Martin, unpublished data). Clutch size for first attempts of Orange-crowned Warblers was 4.76 with renesting attempts being 3.0. Clutch size for first attempts of Red-faced Warblers was 4.5 and repeat attempts was 3.6. First clutch size for Virginia's Warblers was set at 4.0 and renesting clutch size was 3.0. Finally, first clutch size for Gray-headed Juncos was set at 4.0 and for renesting or second broods was 3.9. Mean number of renesting attempts was: Orange-crowned Warblers, 1.65; Red-faced Warblers, 1.80; Virginia's Warblers, 1.60; and Gray-headed Juncos, 3.0. Juvenile survival was assumed to be 0.5 of adult survival following Donovan et al. (1995).

Count data were summed across the 10 plots that were censused in every year, as an index to yearly abundance of each of the four species over the $12 \mathrm{yr}$ of counts. These abundance data were regressed against both May + June (nesting season) and April + May (migration and settlement period) precipitation using 



FIG. 2. Relative humidity and temperature were measured at the top and bottom of the slope at 30-s intervals and averaged over 5 min for 5-d moving averages in late May 1994 and 1996. Probes for measuring microclimate were placed in the same permanent sites each year to control any site effects. Probes at the top were placed near the ground in a locust patch typical of Virginia's Warblers, and probes at the bottom were placed in a maple patch typical of Orange-crowned Warblers (see Fig. 1; Martin 1998).

both linear and log-transformed models; log-transformed results are reported when more variance in the data are explained. Forward selection step-wise regression was used to examine importance of precipitation vs. abundance of other coexisting species on annual abundance of each species. Log-transformed precipitation was used when such models were better predictors of annual abundance.

\section{RESUlts}

\section{Microclimate gradient}

Temperature and relative humidity were sampled at the top of the slope in a locust patch and at the bottom in a maple patch (Fig. 2), typical of nesting sites of Virginia's and Orange-crowned Warblers (Martin 1998). Late May 1994 and 1996 represented a wet and a dry year (Fig. 3). Relative humidity was greater in the bottom than top of drainages in both years (Fig. 2). Temperature was colder in the bottom than top but differences were minimal at night and maximum at midday (Fig. 2). Thus, temperature and relative humidity varied along the gradient. Microclimate differed between years, with relative humidity being much lower in the dry year of 1996 (Figs. 2, 3) and temperatures slightly warmer.

\section{Shifts in macroclimate and position on the slope}

Precipitation during May and June, the months of nest initiation at the Arizona site, can be characterized as wet or dry relative to a 50-yr mean and include three replicate oscillations between wet and dry years over the nine-year period (Fig. 3a). Moreover, those oscillations included the wettest (1992) year on record and one of the driest years (1996). In contrast, minimum $(r=0.05, P=0.90)$ and maximum $(r=-0.40, P=$ 0.29 ) temperatures were uncorrelated with changes in precipitation among years (Fig. 3b, c).

Bird species shifted their nest sites toward higher positions in wet years and toward lower positions in dry years. Shifts were compared between the wet year of 1994 (topographic data were not collected in the extreme wet year of 1992) and the dry year of 1996. Virginia's Warblers reversed their distributions on the slope between these wet and dry years (Fig. 4a: likelihood ratio $X^{2}=19.4, P<0.001, N=76$ ); Virginia's Warblers commonly nested high on the slope, especially in the wet year of 1994 (Fig. 1; also Martin 1998), but they mostly nested in the bottom of drainages in the dry year of 1996 (Fig. 4a). Orange-crowned Warblers did not reverse their distributions because they always use the lower reaches most frequently (Fig. 4d), 

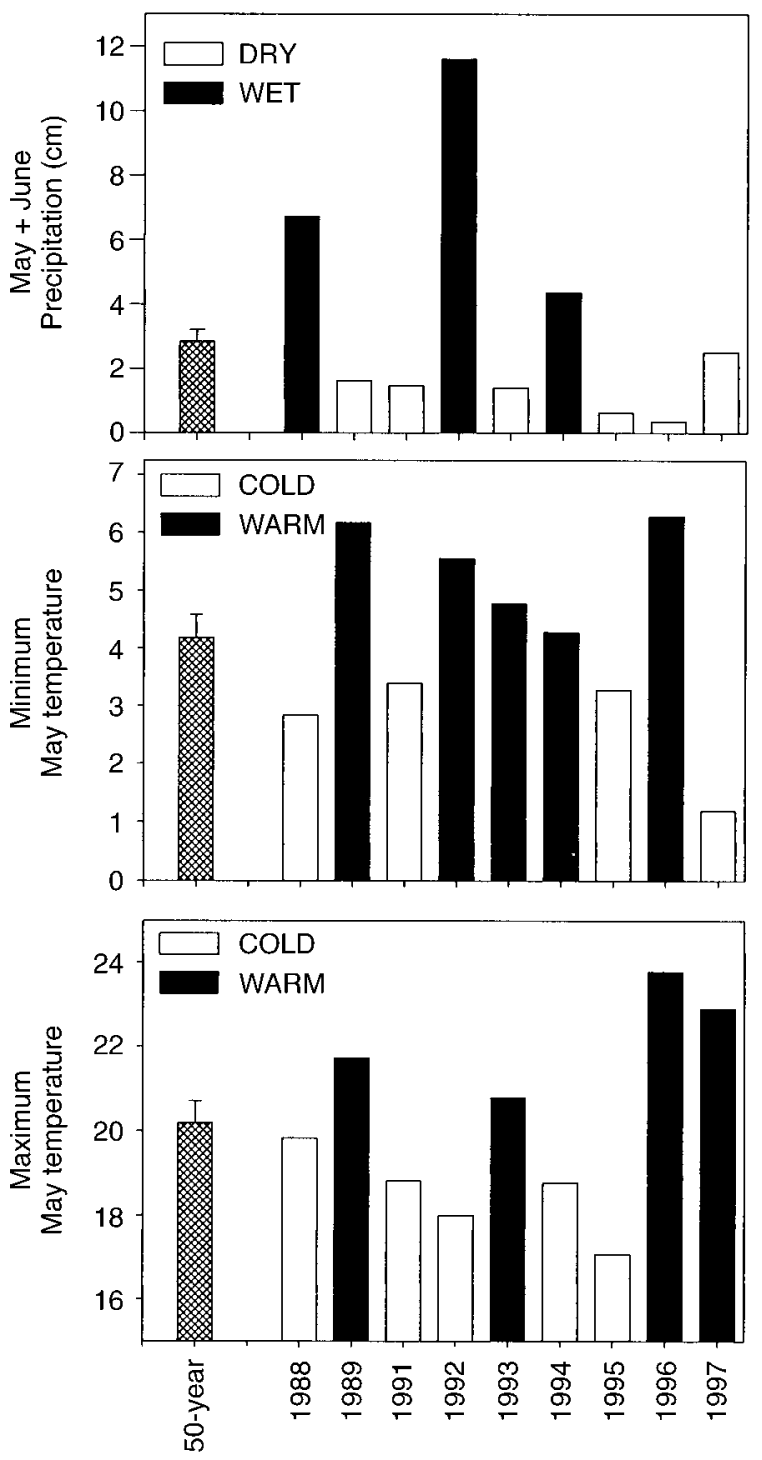

FIG. 3. Total precipitation during May and June (when $>90 \%$ of nests of these species are initiated) for study years from 1988 to present; field data were not collected in 1990. Mean precipitation $(+1 \mathrm{SE}$ ) over the previous $50 \mathrm{yr}$ is provided for comparison to characterize wet and dry years. Note that wet and dry years alternate regularly across the nine study years and included the wettest (1992) year on record and one of the driest (1996).

but increased $\left(X^{2}=6.6, P=0.038, N=92\right)$ their use of middle and upper sites in the wet year of 1994 compared with the dry year of 1996 (Fig. 4d). Gray-headed Juncos did not $\left(X^{2}=0.7, P=0.69, N=127\right)$ shift between wet and dry years (Fig. 4b), whereas Redfaced Warblers showed moderate shifts $\left(X^{2}=5.8, P=\right.$ $0.055, N=78)$ to lower sites in dry years and upper sites in wet years (Fig. 4c).

\section{Microhabitat shifts}

Spatial shifts (Fig. 4) reflect shifts in microhabitats chosen for nesting. I illustrate choice of maple- or lo- cust-dominated sites because those two microhabitats represent the two extremes of the gradient and bird species show significant shifts in use of those two microhabitat types (Fig. 5). As suggested by spatial shifts, Virginia's Warblers showed the greatest shift of the four

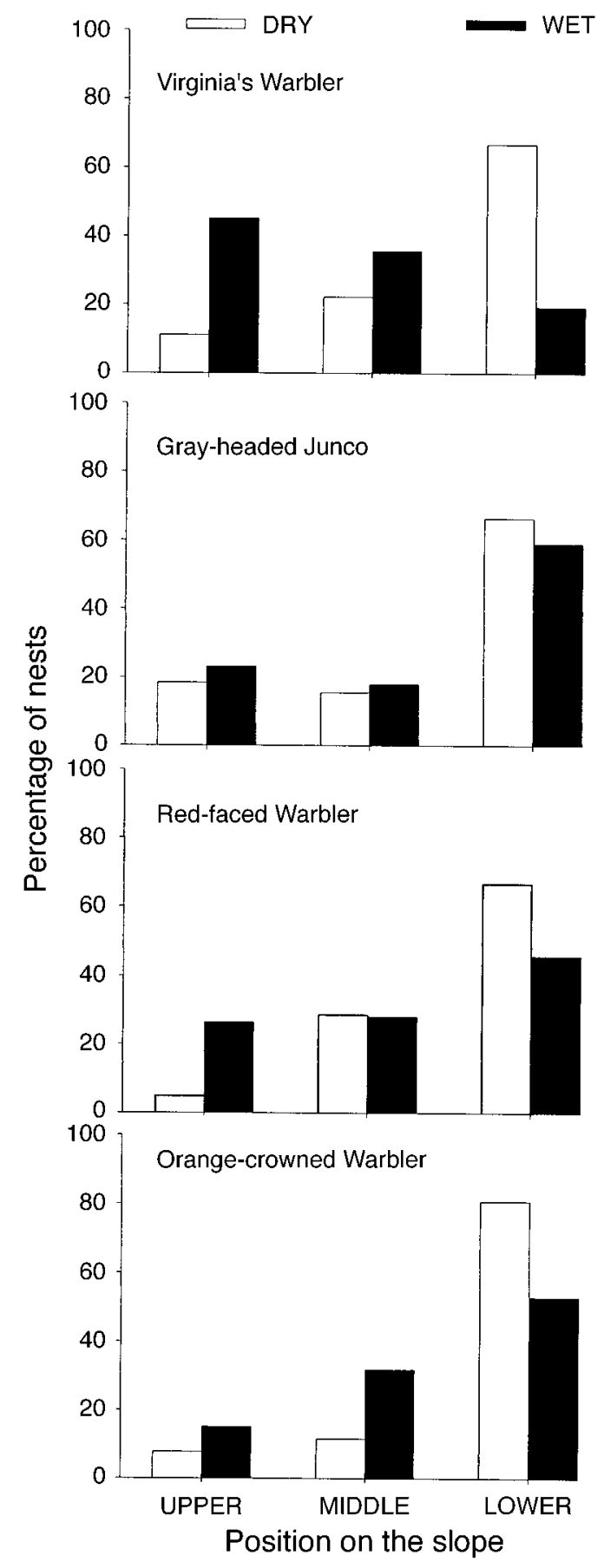

FIG. 4. Proportion of nests placed on the upper, middle, or lower portion of slopes in a wet (1994) and extremely dry (1996) year for each of the four bird species. The upper and lower portions of the slopes represent xeric and mesic conditions, respectively (see Figs. 1, 2). 


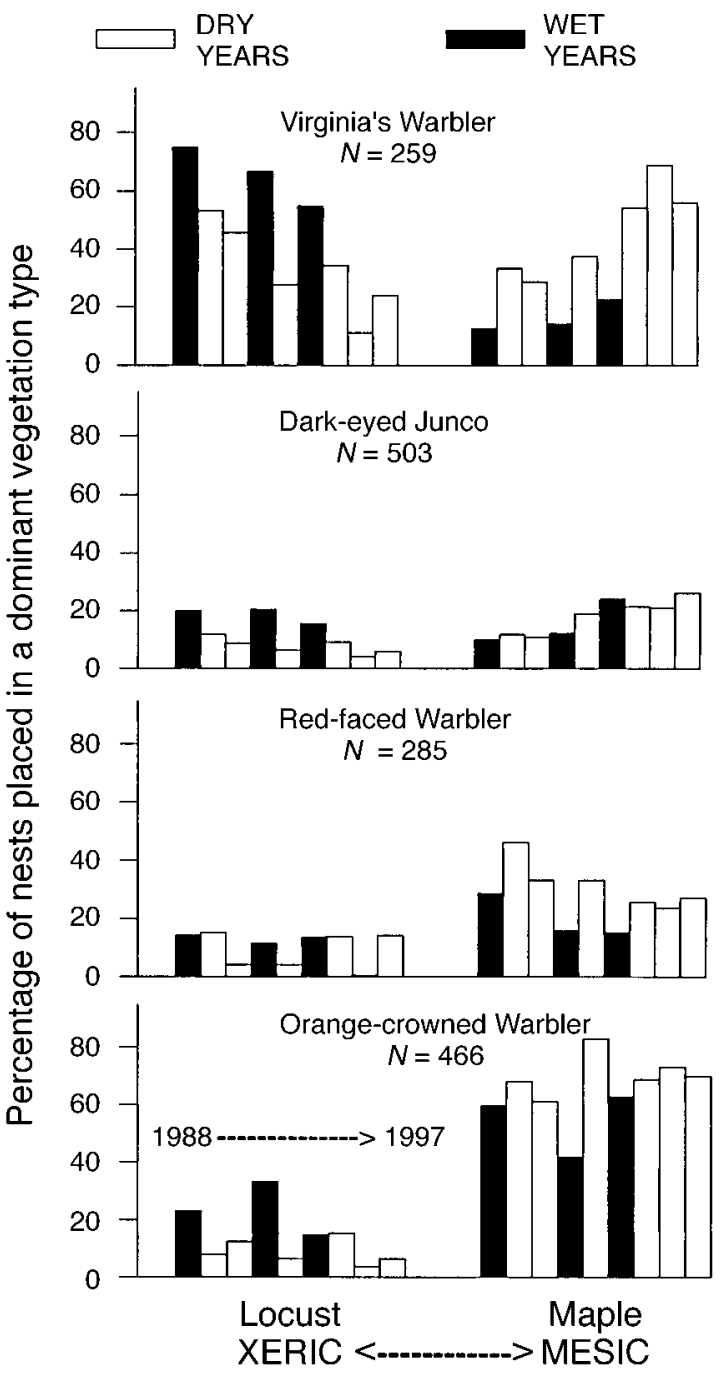

FIG. 5. Percentage of nests placed in locust- or mapledominated vegetation during each of nine years of study for four ground-nesting bird species. Nests in locust- and mapledominated sites are shown because these represent the two ends of the gradient (see Fig. 1) and provide the clearest examples of shifting distributions. Note that preferred dominant vegetation for Gray-headed Juncos and Red-faced Warblers differed from locust and maple (see Martin 1998) such that a large portion of nests are not represented by maple and locust nests. Nonetheless, shifts between these two vegetation types were fairly marked for all four bird species with changes by as much as $20-80 \%$ in use of locust or maple sites between years. Note that shifts oscillate between years with oscillations in precipitation and do not represent a continuous shift in one direction over time.

species in use of maple and locust patches, with use of maple patches decreasing in wet years and increasing in dry years $\left(F_{1,100}=9.8, P=0.017\right)$ while use of locust-dominated patches shows the reverse shifts $\left(F_{1,53}\right.$ $=11.0, P=0.013$; Fig. 5a). Those shifts are extremely large, shifting from $<20 \%$ of nests being placed in maple patches in wet years to $>70 \%$ of nests being placed in maple patches in the dry year of 1996. Re- verse shifts were observed for use of locust, although slightly less extreme as locust is generally used $>30 \%$ even in dry years, with the exception of the extreme dry year of 1996 (Fig. 5a). Note that those shifts oscillate between years with oscillating precipitation (see Fig. 3), providing temporal replication that birds are shifting in response to changing precipitation.

Orange-crowned Warblers showed less dramatic spatial shifts in topographic position on the slopes (Fig. 4d) and similarly showed less dramatic shifts in microhabitat use (Fig. 5d). Nonetheless, Orange-crowned Warblers showed smaller but significant increases and decreases in use of maple-dominated patches in dry and wet years, respectively $\left(F_{1,337}=6.9, P=0.034\right)$. They also shifted in use of locust patches in wet and dry years $\left(F_{1,68}=11.7, P=0.011\right.$; Fig. $\left.5 \mathrm{~d}\right)$.

Red-faced Warblers and Gray-headed Juncos showed minor or no spatial shifts, respectively, and similarly showed less pronounced microhabitat shifts, but each still exhibited some shifts. Red-faced Warblers which tend to use more mesic microhabitats than Gray-headed Juncos showed marginally significant shifts in use of maple $\left(F_{1,70}=4.3, P=0.076\right)$ but not locust $\left(F_{1,27}=\right.$ $1.2, P=0.30$ ) between wet vs. dry years (Fig. 5 b). In contrast, juncos which use more xeric microhabitats showed the opposite pattern of significant shifts in use of locust $\left(F_{1,54}=32.0, P<0.001\right)$ but not maple $\left(F_{1,103}\right.$ $=0.4, P=0.53$ ) in wet vs. dry years (Fig. $5 \mathrm{c}$ ).

Precipitation varied within wet and dry year classifications (Fig. 3) and this continuous variation was examined. All bird species showed a negative correlation between use of maple patches and precipitation, while showing a positive correlation between use of locust patches and precipitation, with insignificant patterns of use of maple by Gray-headed Juncos and of locust by Red-faced Warblers (Fig. 6). In contrast, none of the species showed correlations between use of maple or locust with minimum or maximum temperature $(P>0.15$ in all cases: compare Figs. 3 and 5) with exception that use of locust by Orange-crowned Warblers was negatively correlated with maximum temperature $(r=-0.70, P=0.038)$. Maximum temperature also explained additional variation $\left(r_{\mathrm{p}}=-0.87\right.$, $P=0.005)$ after accounting for precipitation $\left(r_{\mathrm{p}}=0.96\right.$, $P<0.0001)$ in Orange-crowned Warblers. However, neither minimum or maximum temperature explained additional variation in use of either microhabitat by any other species $(P>0.27$ in all cases $)$.

When precipitation and abundance of the other coexisting species were used in stepwise regression, use of locust by Virginia's Warbler was most strongly predicted by abundance of Orange-crowned Warblers (Fig. $7 \mathrm{a}$, while precipitation did not explain any residual variation $\left(r_{\mathrm{p}}=-0.22, P=0.60\right)$. Similarly, use of maple by Virginia's Warbler was most strongly predicted by abundance of Orange-crowned Warblers (Fig. $7 b$ ), while precipitation did not explain residual variation $\left(r_{\mathrm{p}}=0.38, P=0.35\right)$. In contrast, abundance of 

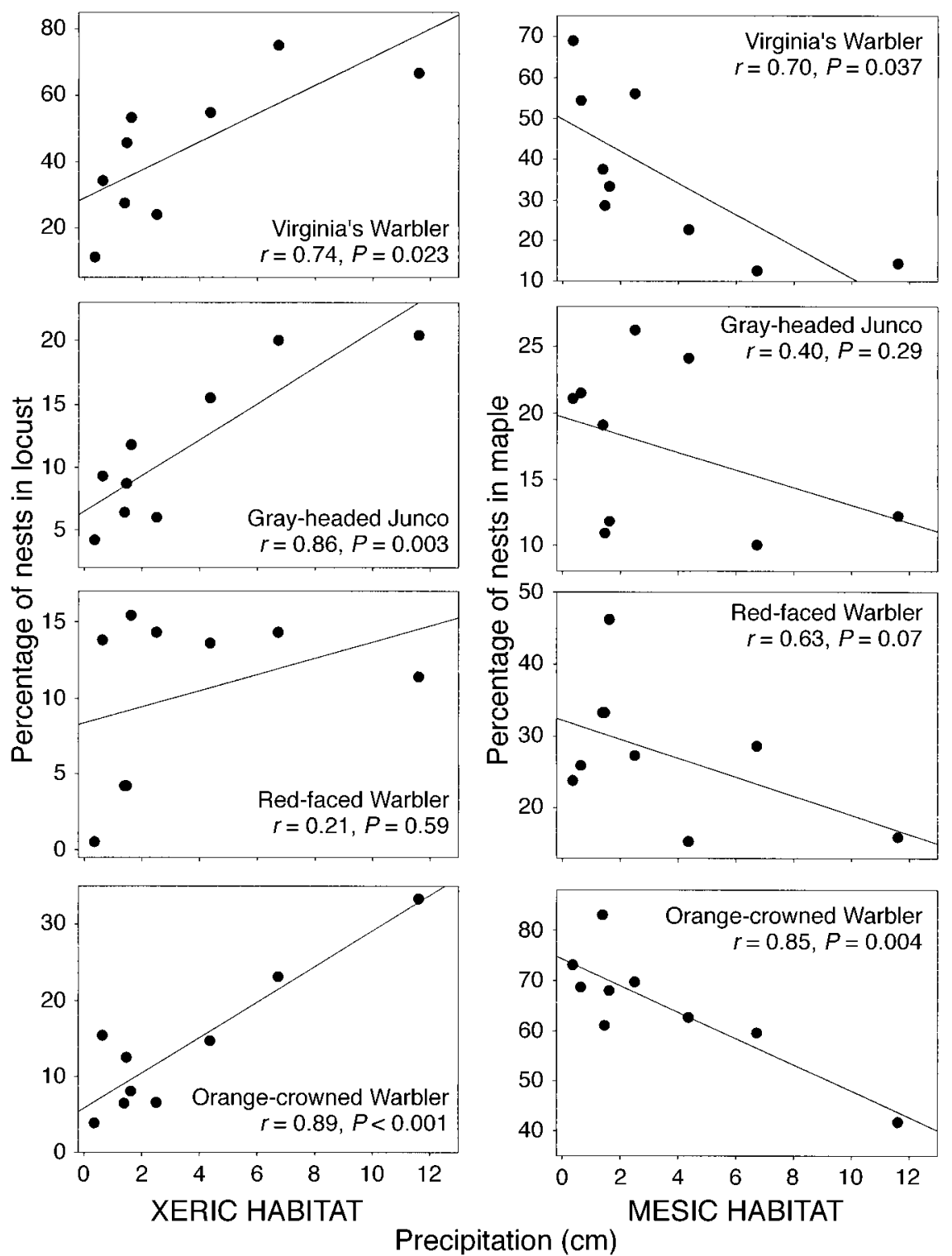

Fig. 6. Correlations between percentage of nests placed in maple and locust patches relative to total May and June precipitation in each of nine study years for each of the four ground-nesting bird species.

other species did not explain any residual variation in use of locust and maple by any of the remaining species; each remained most closely correlated with precipitation (Fig. 6).

\section{Nest success consequences of microhabitat shifts}

The four bird species differed $(P<0.001$ in all cases $)$ in their daily nest survival rates within each nest type (Fig. 8). Each bird species also differed $(P<0.001$ in all cases) among the four nest microhabitat types in their daily survival rates. Each bird species obtained its highest nest success in its preferred vegetation type (Fig. 8), indicating that vegetation preferences are adaptive (Martin 1998). Moreover, success in the preferred vegetation type was greater than for any other species using the same vegetation type (Fig. 8). For example, Orange-crowned Warblers had higher nest success in maple than in any other vegetation types on the gradient and their success within maple patches was higher than for any other bird species using this vegetation type (Fig. 8). Similar patterns are apparent for the other three bird species. Those differences in nest success are due to nest predation because predation accounts for $92 \%$ of nesting mortality. Thus, shifts up or down the gradient away from the vegetation type used most frequently by each bird species induce strong demographic costs from nest predation.

Projection matrix modeling (see Methods) allows estimates of nesting success where populations are self sustaining ( $\lambda=1.0$; i.e., a source population sensu 

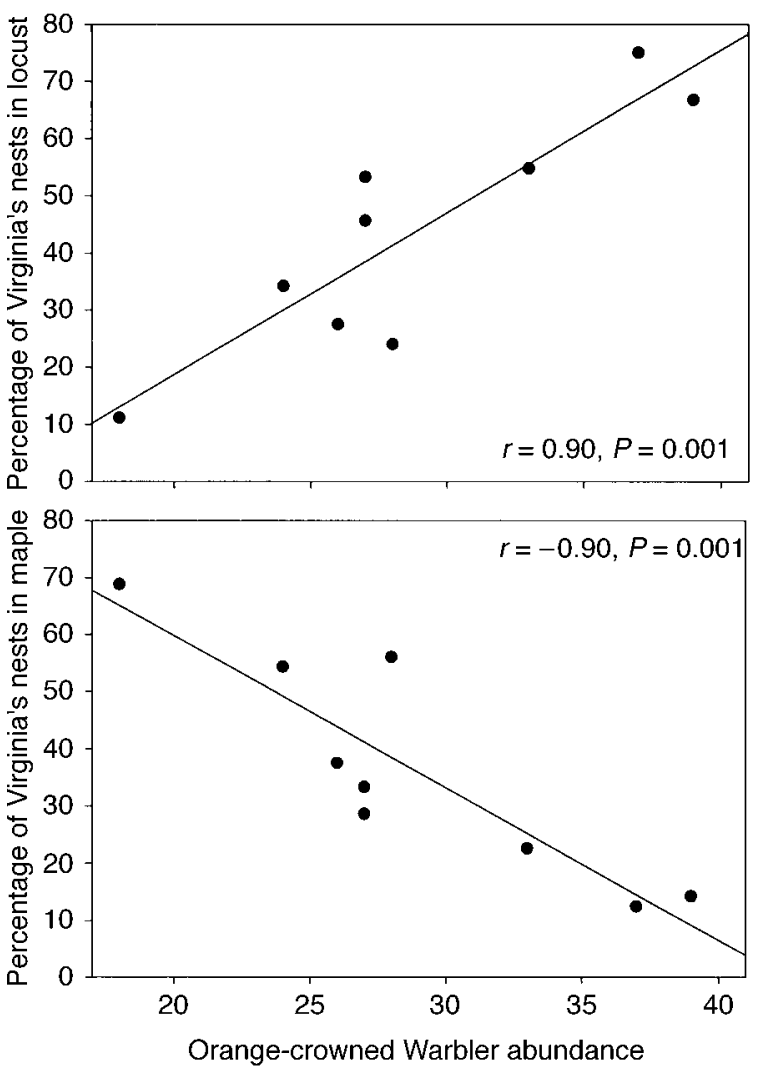

FIG. 7. Correlations between percentage of Virginia's Warbler nests placed in maple and locust patches relative to the abundance of Orange-crowned Warblers in each of nine study years.

Pulliam 1988). The modeling suggests that an estimated nesting success of $36-40 \%$ is needed to achieve $\lambda=1$ in single-brooded warblers (Fig. 8). In contrast, the double-brooded Gray-headed Junco only requires an estimated nesting success of $32 \%$ to achieve $\lambda=1$. Note that all species appear to have nesting success that allows populations to be self sustaining in the veg- etation type used most frequently by that species (Fig. 8 ). In contrast, nest success fell below $\lambda=1$ (i.e., sink populations sensu Pulliam 1988) in all species when they moved up or down the gradient and into other nest sites, with the exception of Virginia's Warblers which achieved a nesting success allowing $\lambda=1$ in maple as well as their most frequently used locust nest types (Fig. 8).

\section{Annual changes in abundance}

The index of abundance (total number of territories counted on 10 plots) was negatively correlated with May + June precipitation from 1985 to 1997 for Virginia's Warbler and Gray-headed Junco (Fig. 9). Orange-crowned Warbler showed a strong positive correlation, while Red-faced Warbler showed no correlation (Fig. 9). On the other hand, Red-faced Warbler may increase with May + June precipitation; if the three high (outlier) years are removed, the remaining nine years show a strong positive correlation $(r=0.87$, $P=0.002$ ). Moreover the three high (outlier) years showed a positive trend, but separate from remaining years, possibly reflecting the influence of some other factor. Thus, the true pattern is unclear.

Very similar results were obtained for April + May precipitation. Virginia's Warbler $(r=-0.71, P=0.01)$ and Gray-headed Junco $(r=-0.62, P=0.03)$ showed negative correlations. Orange-crowned Warbler $(r=$ $0.80, P=0.002$ ) showed a positive correlation and Red-faced Warbler showed no pattern $(r=-0.17, P$ $=0.60)$ with April + May precipitation. Abundance showed no correlation with January through April $(t$ $<1.0, P>0.35)$ precipitation. Correlations were strongest for May + June precipitation in all cases, so May + June precipitation was used for stepwise models.

Stepwise regression showed that precipitation was the primary predictor of abundance of Orange-crowned Warbler and Gray-headed Junco, with no residual variation being explained by abundances of the other ground-nesting species $(t<1.4, P>0.19)$. Red-faced
FIG. 8. Daily survival rates (probability of survival per day $+1 \mathrm{SE}$ ) for nests placed in different microhabitats by the four ground-nesting bird species (VIWA = Virginia's Warbler, GHJU $=$ Grey-headed Junco, RFWA $=$ Redfaced Warbler, OCWA = Orange-crowned Warbler; see Fig. 5 for sample sizes). The approximate percentage of nests that are successful in fledging at least one young is shown on the right-hand $y$-axis for reference. Species and nest microhabitats are ordered from top/xeric to bottom/mesic. The level of nest success required to maintain populations $(\lambda=1.0)$ was estimated using population projection matrices to identify microhabitats in which each species obtains sufficient nest success for self-sustaining populations (demarcated by the dashed lines). Preferred microhabitat (see Martin 1998) is identified with a dagger.

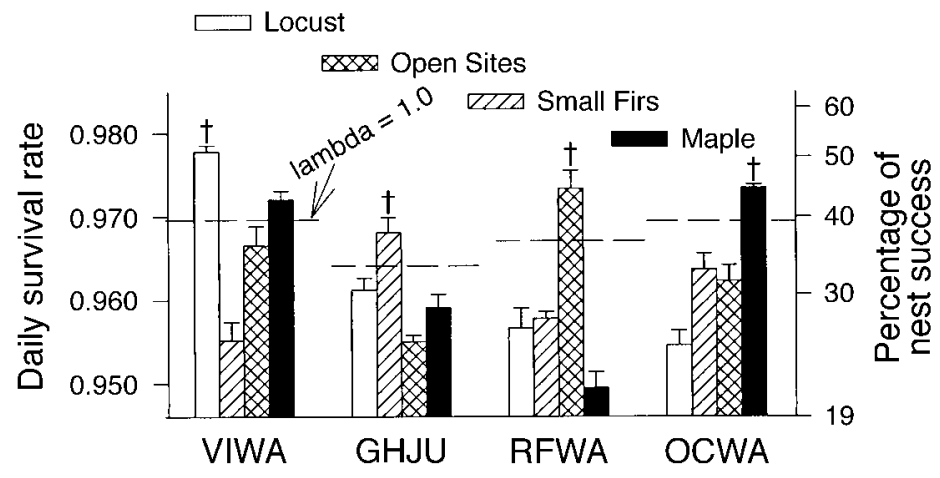






FIG. 9. Correlations of yearly abundance (obtained based on summed counts over 10 study plots studied since 1985) with May and June precipitation for each of the four species over 12 years (from 1985 to 1997).

Warbler showed no correlations with precipitation (see Fig. 9) or the other coexisting species $(r<0.21, P>$ $0.50)$. In contrast, annual abundance of Virginia's Warbler was most strongly negatively correlated with Orange-crowned Warbler $\left(t=-4.8, P<0.001, r_{\mathrm{p}}=\right.$ -0.84 ; see Fig. 10) with precipitation not explaining any residual variation $\left(t=-0.17, P=0.87, r_{\mathrm{p}}=\right.$ $-0.06)$.

\section{DISCUSSION}

\section{Abiotic vs. biotic effects}

Examination of causes of habitat differences among coexisting species often center on biotic processes, such as competition and predation. Differences in habitat use, however, may result from individualistic responses to habitat as a function of differing evolutionary histories (e.g., James et al. 1984, Martin 1986, $1988 a$, Wiens 1989). One way that evolutionary histories may create differences in habitat use of species is through differing physiological tolerances that favor choice of habitats that differ in their underlying climate (Weathers and Greene 1998). Such effects could explain why the four study species are segregated in their nest sites along a microclimate gradient. Yet, temperature and relative humidity differences along the gradient do not necessarily indicate similar differences in vapor pressure, complicating microclimate interpretations for differences in nest-site choice along the gradient. Moreover, vegetation differences along the gradient also could explain nest-site choices (Martin 1998) instead of microclimate. Examination of responses to changing microclimate provides a more powerful way to examine its influence on nest-site choice.

Responses to changing weather showed that local distributions and nesting microhabitats are influenced by microclimate. Birds exhibited clear shifts in distribution along the microclimate gradient (Fig. 4) and among microhabitats (Figs. 5, 6) with dynamic changes in weather among years. Moreover, shifts in microhabitat use oscillated between wet and dry years (Fig. 5) providing temporal replication of responses to changing weather. Those results confirm that habitat use is sensitive to microclimatic conditions and suggest that physiological tolerance may be an important influence on habitat use (Walsberg 1985). Of course, the microclimate gradient observed on my site is steep



FIG. 10. Correlations between yearly abundance (obtained based on summed counts over 10 study plots studied since 1985) of Virginia's Warblers and Orange-crowned Warblers over 12 years (1985 to 1997). 
(rapid changes over short distances). Consequently, patterns observed on my site may be less obvious or nonexistent in local sites at other geographical locations or habitats with less abrupt microclimate gradients. In such situations, gradients may occur over much broader spatial ranges, causing a need to examine larger spatial shifts.

On the other hand, distributional shifts appeared to occur at larger spatial scales at my site as well; three of the four species showed strong shifts in abundance correlated with variation in precipitation among years (Fig. 9). The patterns differed among species, however. Virginia's Warblers and Gray-headed Juncos use xeric habitat most frequently (Martin 1998) and they declined in abundance in wet years (Fig. 9). In contrast, Orange-crowned Warblers and Red-faced Warblers use mesic habitat most frequently (Martin 1998), and Orange-crowned Warbler, and possibly Red-faced Warbler, increased in abundance in wet years (Fig. 9). Those shifts in abundance were correlated with weather during the period of settling and nesting and not with weather in the prior year, suggesting a regional redistribution of birds, possibly during the migratory settling period. Thus, distributional shifts of birds in response to weather may occur at the local microclimate gradient and at some larger regional gradient. The latter provides support for the idea that geographic distributions of birds may be influenced by physiological tolerances and climate gradients at large spatial scales (Hayworth and Weathers 1984, Root 1988a, b, Root and Schneider 1995).

While abiotic factors clearly influence habitat use and distribution, biotic factors also play a role and possibly a bigger role for some species than for others. Statistics suggested that abundance of Orange-crowned Warblers may be more important than precipitation for habitat use and abundance of Virginia's Warblers (Figs. 7, 9). Removal and playback experiments confirmed that Orange-crowned Warblers are behaviorally dominant and directly influence microhabitat use of Virginia's Warblers (Martin and Martin 2001a, b). Thus, weather may indirectly influence Virginia's Warblers by directly affecting Orange-crowned Warblers. Of course, climate may still influence habitat use by Virginia's Warblers; their preference for maple sites in the absence of Orange-crowned Warblers (Fig. 7, Martin and Martin 2001a) may reflect a preference for relatively mesic microhabitats but their extensive use of locust sites indicates a tolerance for xeric microhabitats.

All species also showed strong biotic effects of nest predation on microhabitat choices (Fig. 8). Predation rates were least for each species in the habitat they used most frequently (Fig. 8), indicating that microhabitat preferences are adaptive and under directional selection from nest predation (Martin 1998). Indeed, directional selection from nest predation can be clearly documented because of the direct costs of predation on

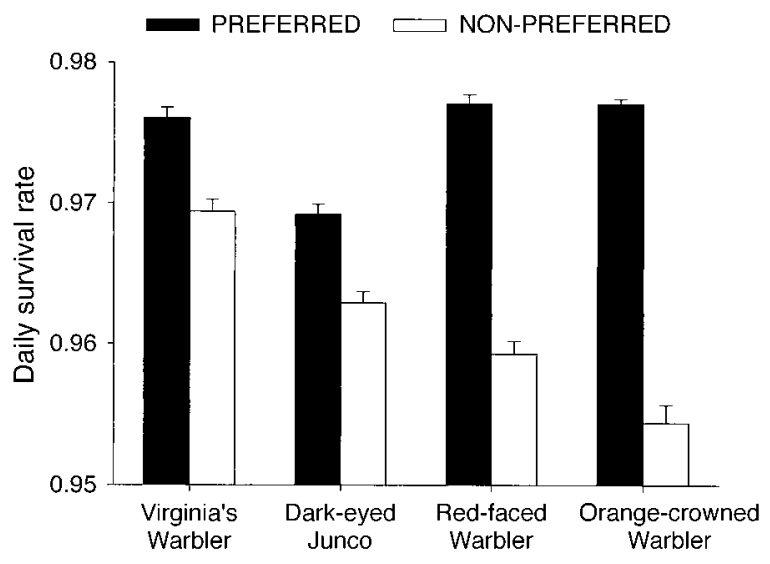

FIG. 11. Daily survival rates (probability of survival per day $+1 \mathrm{SE}$ ) for nests placed in preferred and non-preferred microhabitats. Preferred microhabitats are defined as the vegetation type that is used most frequently and non-preferred microhabitats are all other vegetation types (adapted from Martin [1998]).

reproductive success (Martin 1998). In contrast, directional selection from physiological tolerances and microclimate are less clear given that direct fitness costs of microclimate are undocumented in my system at present. Weather has indirect costs by causing species to shift to microhabitats that yield decreased nesting success (Fig. 8). Moreover, costs of shifting out of preferred microhabitats are greater for species that are lower rather than higher on the gradient (Fig. 11). Those results indicate that costs are greater when shifting up than down the slope; species that are low on the slope (e.g., Orange-crowned Warbler) can only move up the gradient when they shift their nest sites and such shifts up the gradient apparently are more costly than for species high on the slope (e.g., Virginia's Warblers) that can only move down the slope when they shift their nest sites (Fig. 11). Ultimately, nest losses are mostly from nest predation (i.e., 92\% of nest losses), which suggests that abiotic and biotic effects interact.

These nest predation costs arise from shifts in microhabitat choice due to shifts in microclimate. Birds should be willing to incur such predation costs only if microclimate exerts other direct costs that favor shifting choices. Those direct costs may be manifested in several different ways: (1) Changes in precipitation may influence water vapor and gas exchange, and constraints on water vapor conductance may create costs to developing embryos (Romanoff and Romanoff 1949, Carey 1983; but see Walsberg and Schmidt 1992). (2) Changes in precipitation and water vapor can influence energetic expenditure of nestlings and adults (Weathers et al. 1999; C. Olson, W. Weathers, and T. Martin, unpublished data). (3) Changes in nest attendance needs of developing embryos and nestlings with changing precipitation may affect energy expenditure and future reproduction of adults either within the current 
season or future seasons. (4) Changes in precipitation may exert direct costs on energy expenditure of adults through effects on thermoregulation (Weathers et al. 1999) and/or ability and time to forage. Those physiological costs may differ among species with differences in physiological tolerances and adaptations and thereby cause differences in habitat use among coexisting species (Hayworth and Weathers 1984, Weathers and Greene 1998). However, ultimately, habitat use and local distributions of coexisting species probably are the result of interactions between abiotic and biotic factors, as found here, and greater attention to the interactive influences of both biotic and abiotic factors is needed in future studies.

\section{Climate change implications}

Global climate change is widely predicted to cause shifts in distributions of species along latitudinal or other climatic gradients because species are expected to track climate as a function of their physiological tolerances (Davis et al. 1986, Webb 1987, Pastor and Post 1988, Graham and Grimm 1990, Davis and Zabinski 1992, Hart and Shaw 1995, Root and Schneider 1995). Model projections of animal responses to global climate change often assume that animals will follow plants; plants will shift in response to climate change and animals will follow plants because animals are distributed based on habitat preferences (many references in Kareiva et al. 1993). Yet, animals are more mobile than plants and can shift distributions more rapidly, suggesting that animals can shift in direct response to climate and independent of shifts in vegetation. The results presented here clearly demonstrate that birds will shift independent of plants and in direct response to changing weather. Those shifts even cause birds to move out of preferred vegetation, which has strong demographic implications. Shifts out of preferred microhabitat types caused predation costs that yielded nesting success that was below levels needed for populations to maintain themselves ( $\lambda<1$, see Fig. 8), indicating that shifts in distributions to minimize physiological costs could incur biotic costs that would have dramatic consequences for long-term population trends (also see Lodge 1993). The one exception was Virginia's Warbler, which obtained nesting success in maple habitat at a level where $\lambda>1.0$ and, thus, shifts by Orange-crowned Warbler may open up habitat for this species that may allow its population to increase in some areas. Thus, climate change can have different effects on different species.

The shifts in abundance among years (Fig. 9) suggest that distributional shifts also occur at spatial scales larger than the local microclimate gradient. Such results are not surprising because distributions of species along the local microclimate gradient mimic their larger geographical distributions; Orange-crowned Warblers are distributed more northerly and at higher elevations, where it is cooler and moister, than Virginia's
Warblers (Martin and Martin 2001a, Olson and Martin 2000). The correlations of distributions along the local microclimate gradient with larger geographical patterns may allow shifting distributions and habitat use at the local scale to predict similar shifts at larger scales (also see Root and Schneider 1995). However, my local results indicate that shifts can result in species moving out of vegetation and habitat to which they are adapted into new vegetation associations that can cause substantial biotic costs. Moreover, shifts into new macrohabitats can cause coexistence of new assemblages of species that can yield new or intensified biotic (e.g., competition, predation) interactions. These biotic costs that could result from climate change have been ignored and underappreciated (but see Lodge 1993).

Finally, independent and differing shifts among microhabitats also suggest that existing communities may change in the future and tear apart as species respond to climate change independently as a function of differing evolutionary histories and physiological tolerances. In short, the potential consequences of climate change may extend well beyond physiological costs for animals and may have dramatic population and community consequences as animals face both abiotic and biotic costs on their distribution and habitat use.

\section{ACKNOWLEDGMENTS}

This long-term work and associated data would not have been possible without the enthusiastic help of many field assistants over the years. Two anonymous reviewers and W. Weathers made helpful suggestions on an early draft. I thank Arizona Game and Fish Agency, Blue Ridge Ranger Station of the Coconino National Forest, and the Apache-Sitgreaves National Forest for their support of this work. This study was supported by grants from the National Science Foundation (DEB-9527318, DEB-9707598), the BBIRD (Breeding Biology Research and Monitoring Database) program, and Global Change Research Program of the Biological Resources Division.

\section{LiterATURE Cited}

Barker, P. A. 1977. Canyon maple-a colorful mountaineer. American Forests 1977:22-25.

Barker, P. A., D. C. Freeman, and K. T. Harper. 1982. Variation in the breeding system of Acer grandidentatum. Forest Science 28:563-572.

Calder, W. A. 1973. Microhabitat selection during nesting of hummingbirds in the Rocky Mountains. Ecology 54:127134.

Carey, C. 1983. Structure and function of avian eggs. Current Ornithology 1:69-103.

Christman, S. P. 1984. Plot mapping: estimating densities of breeding bird territories by combining spot mapping and transect techniques. Condor 86:237-241.

Clements, F. E. 1916. Plant succession: an analysis of the development of vegetation. Publication number 242, Carnegie Institute, Washington, D.C., USA.

Davis, M. B., K. D. Woods, S. L. Webb, and R. P. Futuyma. 1986. Dispersal versus climate: expansion of Fagus and Tsuga in the upper Great Lakes region. Vegetatio 67:93103.

Davis, M. B., and C. Zabinski. 1992. Changes in geographical ranges resulting from greenhouse warming effects on biodiversity of forests. Pages 297-308 in R. Peters and T. 
Lovejoy, editors. Global warming and biological diversity. Yale University Press, New Haven, Connecticut, USA.

Donovan, T. M., F. R. Thompson, III J. Faaborg, and J. R. Probst. 1995. Reproductive success of migratory birds in sources and sinks. Conservation Biology 9:1380-1395.

Gleason, H. A. 1917. The structure and development of the plant association. Torrey Botanical Club Bulletin 43:463481.

Gleason, H. A. 1926. The individualistic concept of the plant association. Torrey Botanical Club Bulletin 53:7-26.

Graham, R. W., and E. C. Grimm. 1990. Effects of global climate change on the patterns of terrestrial biological communities. Trends in Ecology and Evolution 5:289-292.

Grinnell, J. 1917. The niche-relationships of the California Thrasher. Auk 34:427-433.

Grinnell, J. 1924. Geography and evolution. Ecology 5:225229.

Hadley, N. F. 1969. Microenvironmental factors influencing the nesting sites of some subapline Fringillid birds in Colorado. Arctic and Alpine Research 1:121-126.

Haftorn, S. 1988. Incubating female passerines do not let the egg temperature fall below the "physiological zero temperature' during their absences from the nest. Ornis Scandinavica 19:97-110.

Hart, J., and R. Shaw. 1995. Shifting dominance within a montane vegetation community: results of a climate-warming experiment. Science 267:876-880.

Hays, G. C., and J. R. Speakman. 1993. Nest placement by loggerhead turtles, Caretta caretta. Animal Behavior 45 47-53.

Hayworth, A. M., and W. W. Weathers. 1984. Temperature regulation and climatic adaptation in Black-billed and Yellow-billed magpies. Condor 86:19-26.

Hecnar, S. J. 1994. Nest distribution, site selection, and brooding in the five-lined skink (Eumeces fasciatus). Canadian Journal of Zoology 72:1510-1516.

Hensler, G. L., and J. D. Nichols. 1981. The Mayfield method of estimating nesting success: a model, estimators and simulation results. Wilson Bulletin 93:42-53.

Hinds, D. S., and W. A. Calder. 1973. Temperature regulation of the Pyrrhuloxia and the Arizona Cardinal. Physiological Zoology 46:55-71.

Hines, J. E., and J. R. Sauer. 1989. Program CONTRAST: a general program for the analysis of several survival or recovery rate estimates. U.S. Fish Wildlife Service Fish and Wildlife Technical Report 24.

Holt, R. D. 1977. Predation, apparent competition and the structure of prey communities. Theoretical Population Biology 12:197-229.

Holt, R. D. 1984. Spatial heterogeneity, indirect interactions, and the coexistence of prey species. American Naturalist 124:377-406.

Holway, D. A. 1991. Nest-site selection and the importance of nest concealment in the Black-throated Blue Warbler. Condor 93:575-581.

Horvath, O. 1964. Seasonal differences in Rufous Hummingbird nest height and their relation to nest climate. Ecology 45:235-241.

Howard, R. D. 1978. The influence of male-defended oviposition sites on early embryo mortality in bullfrogs. Ecology 59:789-798.

Howlett, J. S., and B. J. M. Stutchbury. 1997. Within-season dispersal, nest-site modification, and predation in renesting Hooded Warblers. Wilson Bulletin 109:643-649.

Isely, D., and F. J. Peabody. 1984. Robinia (Leguminosae: Papilionidea). Castanea 49:187-202.

James, F. C., R. F. Johnston, N. O. Wamer, G. J. Niemi, and W. J. Boecklen. 1984. The Grinnellian niche of the Wood Thrush. American Naturalist 124:17-47.
Johnson, D. H. 1979. Estimating nest success: the Mayfield method and an alternative. Auk 96:651-661.

Johnson, R. A. 1992. Soil texture as an influence on the distribution of the desert seed-harvester ants Pogonomyrmex rugosus and Mesor pergandei. Oecologia 89:118-124.

Kareiva, P. M., J. G. Kingsolver, and R. B. Huey, editors. 1993. Biotic interactions and global change. Sinauer Associates, Sunderland, Massachusetts, USA.

Karr, J. R., and K. E. Freemark. 1983. Habitat selection and environmental gradients: dynamics in the "stable" tropics. Ecology 64:1481-1494.

Lodge, D. M. 1993. Species invasions and deletions: community effects and responses to climate and habitat change. Pages 367-387 in P. M. Kareiva, J. G. Kingsolver, and R. B. Huey, editors. Biotic interactions and global change. Sinauer Associates, Sunderland, Massachusetts, USA.

MacArthur, R. H. 1958. Population ecology of some warblers in northeastern coniferous forests. Ecology 39:599-619.

Martin, P. R., and T. E. Martin. 2001a. Ecological and fitness consequences of species coexistence: a removal experiment with wood warblers. Ecology 82:189-206.

Martin, P. R., and T. E. Martin. 2001b. Behavioral interactions between two coexisting species: song playback experiments with wood warblers. Ecology 82:207-218.

Martin, T. E. 1986. Competition in breeding birds: On the importance of considering processes at the level of the individual. Current Ornithology 4:181-210.

Martin, T. E. 1988a. Processes organizing open-nesting bird assemblages: competition or nest predation? Evolutionary Ecology 2:37-50.

Martin, T. E. 1988b. On the advantage of being different: nest predation and the coexistence of bird species. Proceedings of the National Academy of Science USA 85: 2196-2199.

Martin, T. E. 1993. Nest predation and nest sites: new perspectives on old patterns. BioScience 43:523-532.

Martin, T. E. 1995. Avian life history evolution in relation to nest sites, nest predation, and food. Ecological Monographs 65:101-127.

Martin, T. E. 1996. Fitness costs of resource overlap among coexisting bird species. Nature 380:338-340.

Martin, T. E. 1998. Are microhabitat preferences of coexisting species under selection and adaptive? Ecology 79: 656-670.

Martin, T. E., I. J. Ball, and J. Tewksbury. 1996a. Environmental perturbations and rates of nest predation in birds. Transactions of the North American Wildlife and Natural Resources Conference 61:43-49.

Martin, T. E., and G. R. Geupel. 1993. Nest-monitoring plots: methods for locating nests and monitoring success. Journal of Field Ornithology 64:507-519.

Martin, T. E., and J. J. Roper. 1988. Nest predation and nest site selection of a western population of the Hermit Thrush. Condor 90:51-57.

Mayfield, H. 1975. Suggestions for calculating nest success. Wilson Bulletin 87:456-466.

Olson, C., and T. E. Martin. 2000. Virginia's Warbler (Vermivora virginiae) Pages 1-16 in A. Poole and F. Gill, editors. The birds of North America, No. 477. The Academy of Natural Sciences, Philadelphia, Pennsylvania, USA, and The American Ornithologists' Union, Washington, D.C., USA.

Pastor, J., and W. M. Post. 1988. Response of northern forests to $\mathrm{CO}_{2}$-induced climatic change: dependence on soil water and nitrogen availabilities. Nature 334:55-58.

Peattie, D. C. 1953. A natural history of western trees. Riverside Press, Cambridge University Press, New York, New York, USA.

Peterson, R. T. 1990. A field guide to western birds. Houghton-Mifflin, Boston, Massachusetts, USA. 
Pimm, S. L., and M. L. Rosenzweig. 1981. Competitors and habitat use. Oikos 37:1-6.

Pulliam, H. R. 1988. Sources, sinks, and population regulation. American Naturalist 132:652-661.

Romanoff, A. L., and A. J. Romanoff. 1949. The avian egg. John Wiley, New York, New York, USA.

Root, T. 1988a. Energy constraints on avian distribution and abundances. Ecology 69:330-339.

Root, T. 1988b. Environmental factors associated with avian distributional boundaries. Journal of Biogeography $\mathbf{1 5}$ 489-505.

Root, T. L., and S. H. Schneider. 1995. Ecology and climate: research strategies and implications. Science 269:334-341.

Rosenzweig, M. L. 1981. A theory of habitat selection. Ecology 62:327-335.

Rosenzweig, M. L. 1985. Some theoretical aspects of habitat selection. Pages 517-540 in M. L. Cody, editor. Habitat selection in birds. Academic Press, New York, New York, USA.

Shine, R., M. J. Elphick, and P. S. Harlow. 1995. Sisters like it hot. Nature 378:451-452.

Shine, R., and P. S. Harlow. 1996. Maternal manipulation of offspring phenotypes via nest-site selection in an oviparous lizard. Ecology 77:1808-1817.

Smith, K. G. 1977. Distribution of summer birds along a forest moisture gradient in an Ozark watershed. Ecology 58:810-819.

Stewart, M. M., and F. H. Pough. 1983. Population density of tropical forest frogs: relation to retreat sites. Science 221:570-572.
Toft, C. A. 1985. Resource partitioning in amphibians and reptiles. Copeia 1985:1-21.

Walsberg, G. E. 1981. Nest-site selection and the radiative environment of the Warbling Vireo. Condor 83:86-88.

Walsberg, G. E. 1985. Physiological consequences of microhabitat selection. Pages 389-413 in M. L. Cody, editor Habitat selection in birds. Academic Press, Orlando, Florida, USA.

Walsberg, G. E., and C. A. Schmidt. 1992. Effects of variable humidity on embryonic development and hatching success of Mourning Doves. Auk 109:309-314.

Weathers, W. W., and E. Greene. 1998. Thermoregulatory responses of Bridled and Juniper titmice to high temperature. Condor 100:365-372.

Weathers, W. W., C. R. Olson, R. B. Siegel, C. L. Davidson, and T. R. Famula. 1999. Winter and breeding-season energetics of nonmigratory White-crowned Sparrows. Auk 116:842-847.

Webb, D. R. 1987. Thermal tolerance of avian embryos: a review. Condor 89:874-898.

Webb, T., III. 1987. The appearance and disappearance of major vegetational assemblages: long-term vegetational dynamics in eastern North America. Vegetatio 69:177-187.

Whitham, T. G. 1980. The theory of habitat selection: examined and extended using Pemphigus aphids. American Naturalist 115:449-466.

Wiens, J. A. 1989. The ecology of bird communities. Cambridge University Press, New York, New York, USA.

With, K. A., and D. R. Webb. 1993. Microclimate of ground nests: the relative importance of radiative cover and wind breaks for three grassland species. Condor 95:401-413. 